\title{
Customer Relationship Management (CRM) Implementation in China: A Case Study of Legend Group
}

\author{
Jun Wu \\ School of Economics and Management, Beijing University of Posts and \\ Telecommunications, Beijing 100876, P.R. China wujun1127@vip.sina.com
}

\begin{abstract}
As more and more enterprises face significant growth and profitability challenges, executives are turning to formulate appropriate customer centric strategies and focus on managing customer relationships to support such initiatives. Combining information technology with relationship marketing, customer relationship management (CRM) systems provide the infrastructure that facilitates long-term relationship building with customers. However, not all firms have been successful in their CRM implementations. Many embody a complex implementation process, especially in developing countries like China. This paper examines the implementation of CRM at Legend group, a leading PC vendor in China, and summarizes the factors that lead to the success of CRM projects in China context based on the framework proposed in the paper. The results from the case study also suggest that people, technology, and business processes are all key enablers in CRM implementation.
\end{abstract}

Keywords: CRM, Critical success factors, Case study

\section{INTRODUCTION}

As the business environment is dramatically changing, companies today face the challenge of increasing competition, expanding markets, and rising customer expectations. Nowadays, executives are turning to formulate appropriate customer centric strategies and focus on managing customer relationships to support such initiatives. Therefore, customer relationship management (CRM) is currently one of the hottest topics in the fields of marketing management and information technology. However, According to P.C. Verhoef et al. [1], the success rate of CRM implementation varies between $30 \%$ and $70 \%$. Hence, key factors of success or failures during CRM implementation have been the subject of active research in recent years. In this study, we examine the whole process of CRM implementation at Legend group, a top leading PC vendor in China, as a case study. Using interpretive approach, we explore the various aspects of the CRM system and summarize the critical success factors for its implementation in China context.

The paper is organized as follows. Section 2 first reviews the literature on CRM implementation. Then, we propose a research framework that integrates the

Please use the following format when citing this chapler:

Wu, J, 2007, in IFIP International Federation for Information Processing, Volume 255, Research and Practical Issues of Enterprise Information Systems II Volume 2, eds. L. Xu, Tjoa A., Chaudhry S. (Boston: Springer), pp. 1441 - 1447. 
implementation process and three key perspectives of CRM to identify the CSFs for CRM implementation. Next, in section 3, we present the background description of Legend, its initiative for CRM and the implementation process of CRM. By the way, we also analyze the key success factors affecting CRM project through proposed framework. Finally, section 4 draws conclusions from the work in terms of its practical relevance and theoretical implications.

\section{CRM IMPLEMENTATION FRAMEWORK}

\subsection{Literature Review of CRM Implementation}

CRM system implementation is commonly used in functional areas such as customer support and service, sales and marketing. Hahnke describes the CRM lifecycles as consisting of three stages: Integration, Analysis and Action [2].

In the first stage, The CRM lifecycle involves two related objectives: one, to provide the organization and all of its customer-facing employees with a single, complete view of every customer at every touch point and across all channels; and, two, to provide the customer with a single, complete view of the company and its extended channels [3]. The output from this stage is a centralized source of all relevant customer data. Its benefits include improved front office efficiency and productivity [2].

The second stage, as Hahnke called Analysis, is the most critical to CRM success. CRM analytics enable the effective management of customer relationships. Using CRM analytics, organizations are able to analyze customer behaviors, identify customer-buying patterns and discover causal relationships [2].

The final phase, Action, is where the strategic decisions are carried out. Business processes and organizational structures are refined based on the improved customer understanding gained through analysis. This stage closes the CRM loop and allows organizations to cash in on the valuable insights gained through analysis [2].

On the other hand, successful CRM implementation often entails significant organizational transformation due to the complexity of multiple operations involved in managing customer relationships [5]. Implementing a CRM system is only part of the needed change. To embrace the new ways of interacting with customers, firms need to align various organizational aspects with their CRM systems, e.g. business processes, strategies, top management support, and employee training [6]. These organizational efforts are termed as organizational capital and must take place in conjunction with technology investments [7]. In a word, we should take a holistic approach to explore the factors affecting CRM implementation.

\subsection{Conceptual Research Framework}

Based on the CRM literature and the discussions above, the conceptual research framework is developed and depicted in Fig 1. A typical CRM implementation can be 
classified into six iterative processes including Exploring and analyzing, visioning, building business case, planning and designing solution, implementing and integrating, and realizing value. Three key perspectives of CRM, i.e. people, process, and technology are proposed. Deliverables and services for major processes are also illustrated in the framework in bold letters. This framework builds the theoretical foundation for the case study in the next section.

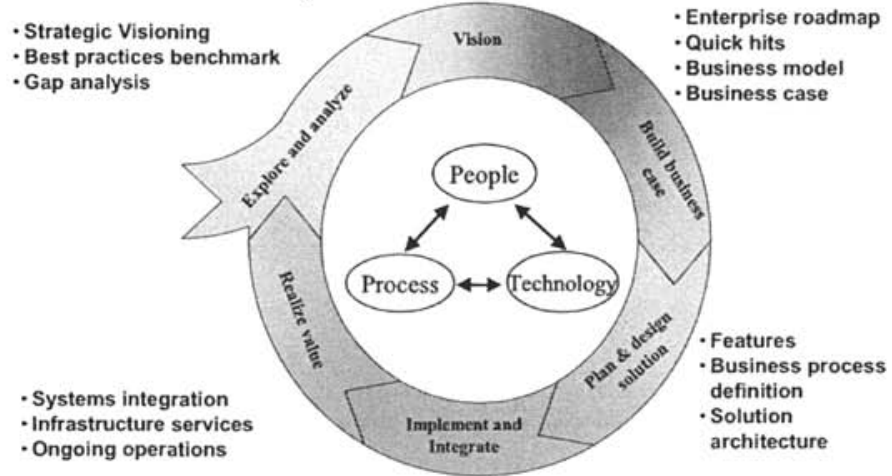

Figure 1. CRM Implementation Framework

\section{CASE STUDY: LEGEND GROUP}

\subsection{Company Profile}

Legend group was set up in 1984 by 11 computer scientists with RMB200, 000 (US $\$ 25,000$ ) in seed money. The group's principal activity is the development, manufacturing and marketing of information technology products including desktop and notebook PCs, displays, storage drives, and IT services. According to IDC report, it has been in the leadership position in China for eight consecutive years with over $25 \%$ market share in 2004 [8]. The development history of the company can be classified into two different phases: In phase one, 1984-2001, Legend were more domestic market oriented, with over $50 \%$ annual growth rate from 1997 to 2000 . In phase two, 2002- present, Legend changed its brand name to Lenovo in 2003 and acquired IBM's PC operations for approximately $\$ 1.75$ billion in 2005 [8]. The company now remains a PC leader in China, but it has a global presence, with approximately $\$ 13$ billion in annual revenue, and products serving enterprises and consumers the world over [8]. As CRM system implementation in the company begun from 2001 and rolled out in the end of 2002, we use the old brand name, Legend, to refer to the company and discuss the issues based on the business environment in that period of time. 


\subsection{CRM Initiatives}

Legend began implementation of information systems (e.g., sales, service) early in the 1990s. However, these systems were stand-alone applications as they had little interaction with customers and were restricted in analytical capabilities. On the other hand, Although Legend was China's No. 1 PC vendor with annual sales about 2.5 million PC units sold in 2000; the company also faced significant growth and profitability challenges. The background of Chinese PC market and Legend's business challenges are summarized in the table 1 below.

Table 1. Motivations for Legend Implementing CRM

\begin{tabular}{|c|c|}
\hline hinese PC market & Busin \\
\hline $\begin{array}{l}\text { Increasing preference for custome } \\
\text { self control and personalization. }\end{array}$ & $\begin{array}{l}\text { Client-support frame (wo } \\
\text { technique and data) cannot sust } \\
\text { customers' personalized service re }\end{array}$ \\
\hline is under serviced not & $\begin{array}{l}\text { Separately saved cus } \\
\text { information is not integrated, and } \\
\text { be fully shared. }\end{array}$ \\
\hline $\begin{array}{l}\text { New customer service deliv } \\
\text { channels. }\end{array}$ & $\begin{array}{l}\text { Lac } \\
\text { of mar }\end{array}$ \\
\hline $\begin{array}{l}\text { Rising Customer Expectations, } \\
\text { Increasing demand for total solutions } \\
\text { from large businesses. }\end{array}$ & $\begin{array}{l}\text { mant lack of proper } \\
\text { Ind measures to follow up, so } \\
\text { the sales opportunity and keep } \\
\text { the clients. }\end{array}$ \\
\hline
\end{tabular}

Central to these challenges is the need to understand the quality of its customer base and target the highest value market segments and deliver services that satisfy the needs of these target segments.

\subsection{Implementation Process}

In order to apply the framework proposed in 2.3 to the real situation, we summarize the case study results for the each stage of the CRM implementation in Legend in table 2.

Table 2. Case Study Data

\begin{tabular}{ll}
\hline Implementation phase & Implementation Details \\
\hline Explore and analyze & With the help of Deloitte Consulting, Legend first took a \\
& CRM audit including strategic visioning, understanding \\
& market best practice, Developing processes from a \\
& customer-centric perspective, Identifying areas lacking, \\
& moving towards major process change, and thus CRM \\
& Implementation. \\
Through CRM strategy assessment, Legend should: (1) \\
Vision & Segmenting and developing 'touch-point' strategies to \\
& support CRM. (2) Implementing and executing the \\
\hline
\end{tabular}


Build business case

Plan \& design
solutions

Implement integrate

Realize value processes, performance measures, IT infrastructure and marketing programs to support CRM capabilities. (3) Managing the delivery of a significant transformation project, including interdependent changes in people, process, systems and technology.

Legend set the enterprise wide CRM roadmap, system construction in 3 phases based on mass planning, phasingout implementation principle. Phase 1, Implementing standard CRM solutions. Phase 2, System deploying and optimizing. Phase 3, System integration with other applications.

Toward building a world-class CRM system, Legend chose Siebel systems, a world leading CRM solution vendor, as strategic partner. They also developed a detail plan to implement the system, aiming at covering the marketing, sales and service functional area.

and Based on Sieble's eRoadmap implementation methodology, the project team first implemented Siebel campaign and sales solutions for Legend's marketing and large account divisions respectively and then implemented Siebel field service for customer service division and Siebel eChannel solutions for both sales and service partners. During the implementation, Siebel consultant took the responsibilities of project level planning, team's building, deliverable definitions, providing technical solutions, and the joined project management, resource alignments, and task level planning and execution. Legend's IT professionals fulfill most of the analysis, development, testing, and integration between sales force, customer care, customer service, telemarketing, web, field service, and transaction system processes and technology.

Based on the field investigation, We find that there is a significant time lag in Legend in terms of productivity gains from its CRM adoption. Marketing, service and analytic functionality have a significant effect on productivity in one to two years right after CRM adoption, due to the fact that accumulating customer data and learning customer behavior pattern takes time, which lead to the relatively long time lag of CRM productivity effects.

\subsection{Critical Success Factors}

Based on the insights gained from Legend CRM implementation process, critical success factors along with people, process and technology dimensions are identified as follows. 


\subsubsection{Technical Factors}

When reviewing Legend CRM projects, we find that project teams' technology choices are directly tied to solving specific business challenges. The bottom line is that they select technology that supports their processes, versus expecting their processes to change to accommodate technology. When selecting CRM tools, Legend side does not just focus on what a product does, but how it does it. They select the solutions that best fit their own internal information system strategies and take a view on its integration capabilities; versus attempting to change their technology plans to accommodate a vendor. Thus, implement relevant technology and intelligent use of technology are key technical perspective for the later CRM adopter to consider.

\subsubsection{Business Process Factors}

In the initial stage of the project, Legend reviewed its as-is processes, aiming at building an enterprise-wide customer-centric business model. Later, they took a continuous effort to redesign its core business processes starting from the customer perspective and involving customer feedback. By doing these works, Legend teams discovered the most important problems they need to target for solution, and they created a baseline of performance that they could use for comparison after the new systems were installed. This process makes the rest of the project flow much easier. So, commitment to process is also important when implementing the CRM system. By the way, change management, management support, and organizational structure also should be highlighted when implementing BPR [9].

\subsubsection{People Factors}

While both technology and business processes are both critical to successful CRM system, it is the end users who are the building blocks of customer relationships. There are several underlying dimensions surrounding management and employees that successful CRM implementations require.

The human side of reengineering is often neglected in CRM implementation. As revealed in the case, objections and disagreement among various functional departments that arise in the process of business reengineering were finally solved through personal intervention by top management. They served as a visionary and a motivator to influence the level of CRM innovations and diminish resistance to change.

CRM initiatives require vision and every employee must understand the purpose and changes that CRM will bring. In the case, Legend first took an organizational CRM readiness assessment including all level people to identify key enablers for the CRM mindset. Later, Company developed detailed plan for training end-users. By having CRM users work with the implementation team from the beginning of the project, this facilitated the implementation process and lead to speedy and successful implementation of the system. More specifically, as CRM were just staring up in Chinese market in 2000, any enterprise which could not fully understand CRM would be driven in to the hot water and at an information asymmetric status. Thus, effective knowledge transfer and knowledge sharing changed the role of the people from passive acceptance to active involvement. 


\section{CONCLUSIONS}

This case study aims to improve better understanding of CRM implementation and both generic and unique critical factors that affect CRM implementation success in China context. In this paper, we have presented a research framework integrating siximplementation phase and three perspectives of CRM as the theoretical base for case discussion. Drawing on the successful CRM experience of a leading computer manufacturer in China, we have shown that CRM implementation is a 'Triple Play' that combines people, technology, and processes. To improve the odds of CRM success, companies need a shift in paradigm from viewing CRM implementation as a large-scale IT project to a holistic business undertaking. The emphasis should lie on CRM providing a business solution and not necessarily an IT solution.

\section{ACKNOWLEDGEMENTS}

This paper is based upon work supported by F0607-35, Key Laboratory of Information Management and Economics, MII, P.R.C. The author would like to thank Professor Xu Yang for his kindly help.

\section{REFERENCES}

1. P.C. Verhoef and F. Langerak, Eleven misconceptions about customer relationship management, Business Strategy Review. Volume 13, Number 4, pp.70-76, (2002).

2. J. Hahnke, The Critical phase of the CRM lifecycle: without CRM analytics, your customer won't even know you're there (2001). http://www.hyperion.com/crm/16536.pdf (Accessed Mar. 6, 2002).

3. J. Galimi, CRM IT Requirements and Strategies for Payer Organizations, in Strategic Analysis Report. eds. J. Galimi (Gartner: Stamford, CN, 2000), pp.213-230.

4. J. Karimi, T.M. Somers, and Y.P. Gupta, Impact of information technology management practices on customer service, Journal of Management Information Systems. Volume 17, Number 4, pp.125-158, (2001).

5. D.L. Goodhue, B.H. Wixom, and H.J. Watson, Realizing business benefits through CRM: Hitting the right target in the right way, MIS Quarterly Executive. Volume 1, Number 2, pp.79-94, (2002).

6. E. Brynjolfsson, L.M. Hitt, and S. Yang, Intangible assets: Computers and organizational capital, Brookings Papers on Economic Activity. Number 1, pp.137-198, (2002).

7. Anonymous, Legend (Lenovo) Annual/Interim report 2000-2005, Lenovo. http://www.pc.ibm.com/ww/lenovo/investor relations.html (Accessed May 6, 2007).

8. M. Al-Mashari and M. Zairi, BPR implementation process: an analysis of key success and failure factors, Business Process Management Journal. Volume 5, Number 1, pp.87112, (1999). 